\title{
Stress analysis of over-denture abutments treated with two obturation techniques
}

\author{
Ahmed N. Elsherbini ${ }^{1}$, Mohamed M Nagy ${ }^{2}$, Nancy N Elsherbini ${ }^{3}$ \\ ${ }^{1}$ Prosthodontics Department, Modern Sciences and Arts University, Cairo, Egypt \\ ${ }^{2}$ Endodontics Department, Ain Shams University, Cairo, Egypt \\ ${ }^{3}$ Prosthodontics Department, Cairo University, Cairo, Egypt
}

\section{Abstract}

Aim: Evaluation of stresses induced on over-denture abutments endodonticaly treated with two different obturation techniques.

Materials and Methods: 4 pesudo-realistic models were fabricated with two remaining canines as abutments. One canine was treated with lateral obturation technique and the other with vertical obturation. An over-denture was fabricated on the model. Then strain gauges were attached on the coronal one third of the root buccally and lingually. $50 \mathrm{~N}$ were applied on the middle of the model using universal testing machine and readings were collected.

Results: From the collected data the lateral obturation showed $85.25 \pm 104.901 \mu \varepsilon$ and the vertical obturation showed $4.875 \pm 3.555 \mu \varepsilon$ with significance difference of $\mathrm{P}<0.05$ between the groups.

Conclusion: It can be concluded that the abutments treated with vertical obturation techniques reduced the stresses induced to the supporting structures when compared with the lateral condensation technique.
Keywords: Over Denture; Abutments; root canal obturation; endodontic obturation technique; stress analysisdentists.

Citation: Elsherbini A, et al. (2021) Stress analysis of over-denture abutments treated with two obturation techniques. Dentistry $\quad 3000 . \quad 1: 0001$ doi:10.5195/d3000.2021.156 Received: March 01, 2021

Accepted: July 19, 2021

Published: August 18, 2021

Copyright: (C2021 Elsherbini A, et al. This is an open access article licensed under a Creative Commons Attribution Work 4.0 United States License.

Email: ahmed_elsherbini@live.com

\section{Introduction}

Over-denture is one of the basis treatment options, over-dentures can be either tooth supported or implant supported. In an overdenture the abutments support the prosthesis and share in bearing the forces induced by the masticatory forces. Forces induced can have severe complications if their values are above the threshold of the abutments and the surrounding structures. Such complications include loss of the abutments, peri-apical lesions, periodontal diseases, and fracture of the abutments EITTINGER and QIAN 1.

\section{Over-denture designs}

There are different types of preparations of the abutments in tooth over-dentures: When crown-root ratio is favorable telescopic crown is usually used in over-denture cases as it provides support and retention, besides to the advantage of directing forces along long axis of the abutments. Abutments usually do not need endodontic treatment ELSHERBINI2. The conventional over-denture with bare root dome shaped preparation with an amalgam plug is one of the mostly advocated over-dentures. Usually two abutments bilaterally positioned are indicated in the conventional over-denture and the abutments are prepared to be $2-3 \mathrm{~mm}$ from the gingival level. In this type of over-dentures endodontic treatment for the abutments are required. It's usually indicated with unfavorable crown-root ratio. A modification of the bare dome shaped root is a metal coping covering the root, proving adequate support and 
protecting the abutment from falling forces. The height of the abutments in the conventional type is $2-3 \mathrm{~mm}$ from gingival margin. Abutments with metal coping showed high susceptibility of gingival inflammation, and root caries, percentage of metal copings loss were high, however the incident of the mobility of the abutments recorded was low ELSHERBINI2, CHABARA et al. 3. Another form is the over-denture retained with attachments; numerous attachments have been used with varying success rates, some have proved high performers and improved patients' quality of life. However they had some drawbacks, as wear of retention by time, high maintenance requirements, fracture of the attachment, in addition to their high costs. Attachments can be used with either tooth and implant supported over-denture NICOLOVSKA et al. 4. Overdentures with short coping and the ones with attachments showed no difference in the preservation of the remaining teeth SCHUHA et al.5. In a systematic review of implants, the use of different attachments designs in over-dentures didn't seem to have an effect on the marginal bone loss around the abutments CEHERLI et al.6.

\section{Endodontic treatment}

The abutment apparatus bearing the load consists of the tooth structure, periodontal ligament, and the endodontic treatment.

Cold lateral condensation has been always the golden standard in endodontic obturation. However, it has been found that this technique depends on the root canal sealer to fill any discrepancies within the main canal or the presence of any accessory anatomy NGUYEN7. Moreover, lack of adaptation, spreader tracts, and voids, have been reported WELLER et al. 8 et.al. Additionally, compaction forces during lateral condensation might cause detrimental stresses to the surrounding root canal dentin SOROS et al. 9. Thermoplasticized, injectable gutta-percha has been found to be significantly superior to lateral condensation in terms of better adaptation to the threedimensional root canal anatomy with minimal voids BUDD et al. 10 and minimum stresses during obturation procedure TELLI et al.

11. Stresses induced during obturation might have future effect on root dentin affecting the long term survival of the tooth specially when used as an abutment liable to extra undue stresses.
What about changing the obturation technique in the endodontic treatment of the abutments in the conventional over-denture?!

\section{Material and Methods}

A pseudo- realistic model, with two natural canines as the remaining abutments was selected for the study. For the reliability of the study four models were fabricated, 8 canines were selected with the same height and stored in saline, to have same environment for all models. In each model, of the two canines, one was treated with vertical obturation technique, the other the canines was treated with lateral obturation technique. The ridge for all models was covered with pseudo mucosa of $3 \mathrm{~mm}$ thickness.

\section{Endodontic treatment of the} abutments

A total of 8 sound mandibular canines of average length $25.25 \pm 0.95 \mathrm{~mm}$ were used. Access cavity was done using a suitable sized-round bur and refined using a diamond stone with rounded end. The working length was determined by introducing a size $10 \mathrm{~K}$-file (Mani Inc.) in the canal until the tip of the file became visible at the major apical foramen under a dental operative 
microscope (SEILER IQ) at x10 magnification. The rubber stopper was then carefully adjusted to the reference point and the distance between the rubber stopper and the file tip was measured approximately to the nearest 0.5 $\mathrm{mm}$. The canal was checked using a size $15 \mathrm{~K}$-file to ensure the initial canal size before canal enlargement. The canal was enlarged using ProTaper Next DENTSPLY SIRONA in the following sequence; X1 (0.17/0.04), X2 $(0.25 / 0.06), X 3(0.30 / 0.07), X 4$ (0.40/0.06), and X5 (0.50/0.06) according to the manufacturer recommendation using a continuous rotation movement at $300 \mathrm{rpm}$ and $2 \mathrm{Ncm}$ powered by the X-Smart Plus endodontic motor DENTSPLY SIRONA up to the working length. Patency was checked after the use of each file using a size $10 \mathrm{~K}$-file. During instrumentation, the canal was irrigated using $20 \mathrm{~mL}$ of $2.6 \%$ sodium hypochlorite, which was used between each file. After instrumentation, the canal was irrigated with $5 \mathrm{~mL}$ 17\% EDTA and a final rinse with $5 \mathrm{~mL} 2.6 \% \mathrm{NaOCl}$. Canals were then dried with size \#50 absorbent paper points and stored in an incubator at $37{ }^{\circ} \mathrm{C}$ and $100 \%$ humidity until obturation.

4 canines were obturated using lateral condensation technique whereas the other 4 canines were obturated using vertical compaction technique.

For lateral condensation, a standardized gutta-percha master point size \#50, 2\% taper META BIOMED was selected, checked and introduced into the root canal to full working length. AH plus sealer DENTSPLY DE TREY GMBH, was mixed according to the manufacturer's recommendations. The master cone was then coated with a sealer and introduced into the root canal until the working length was reached. Lateral condensation was performed using standardized finger spreader size \#30 (Mani Inc.). Gutta Percha points size \#25 was used as accessory cones until the whole canal was filled. Excess Gutta Percha was trimmed using hot burnisher till the orifice of the canal. The access was then sealed using composite resin $3 \mathrm{M}$ ESPE.

Regarding vertical condensation, $\mathrm{A}$ master gutta-percha cone size 50 , $4 \%$ taper (Meta Biomed) was fitted $0.5 \mathrm{~mm}$ short of working length. The gutta-percha cone was coated with AH Plus sealer and inserted into the root canal, and down-packing was performed with a heated suitable sized plugger at $220^{\circ} \mathrm{C}$ E AND Q PLUS SYSTEM, META DENTAL CORP. using the continuous wave of condensation technique. Backfilling was completed with warm gutta- percha from ( $E$ and $Q$ plus system obturation unit. Excess filling material was removed at the level of the orifice. The access was then sealed using composite resin $3 \mathrm{M}$ ESPE.

Subsequently, all teeth were radiographed in bucco-lingual and mesio-distal directions to evaluate the quality of filling for adequacy. Teeth were then stored in an incubator at $37 \circ \mathrm{C}$ and $100 \%$ humidity until further use.

Fabrication of the models

A wax replica of the model required was prepared, stone replica of the canines were inserted in the wax model, surrounded by $1 \mathrm{~mm}$ thickness of aluminum foil to act pseudoperiodontium. Putty index was taken of the stone canines to register their position. Stone replica was used to avoid any distortion to the obturation by the heat used during acrylic processing. Model was flasked, wax elimination, packing of the clear acrylic resin VERTEX, and processing was done. The model was deflasked and finished. The stone canines and aluminum foil were removed; the natural teeth with vertical obturation were placed in the putty index and guided to its position. Tissue mimic GENESIS material was injected in the sockets of the 
canines. Preparation of the canines was done, reducing the clinical crown to $3 \mathrm{~mm}$ from the gingival margin. Afterwards a vacuum stent was made of the model to record the current situation. The acrylic ridge was reduced by $3 \mathrm{~mm}$ to make a space for the pseudo mucosa; silicon adhesive was sprayed on the prepared areas. The vacuum stent was filled with tissue mimic material and placed back on the model. The tissue mimic formed the pseudo mucosa on the model. The same exact procedure was done for the other 3 models.

\section{Testing Procedure}

Strain gauge was attached on the buccal and lingual surfaces of the coronal one third of the roots of the abutments, and placed on the universal testing machine. A metal rod was placed horizontally on the premolar- molar area, and a $50 \mathrm{~N}$ load was applied on the middle of the metal rod and readings were collected. The same procedure was repeated for the 4 models. A total of 80 readings were collected from each canine in each model. Statistical analysis was performed by independent student's T-Test using SPSS 20.0 (SPSS Inc.). A significant difference was observed when $p<0.05$ Fig.1 (a-b).

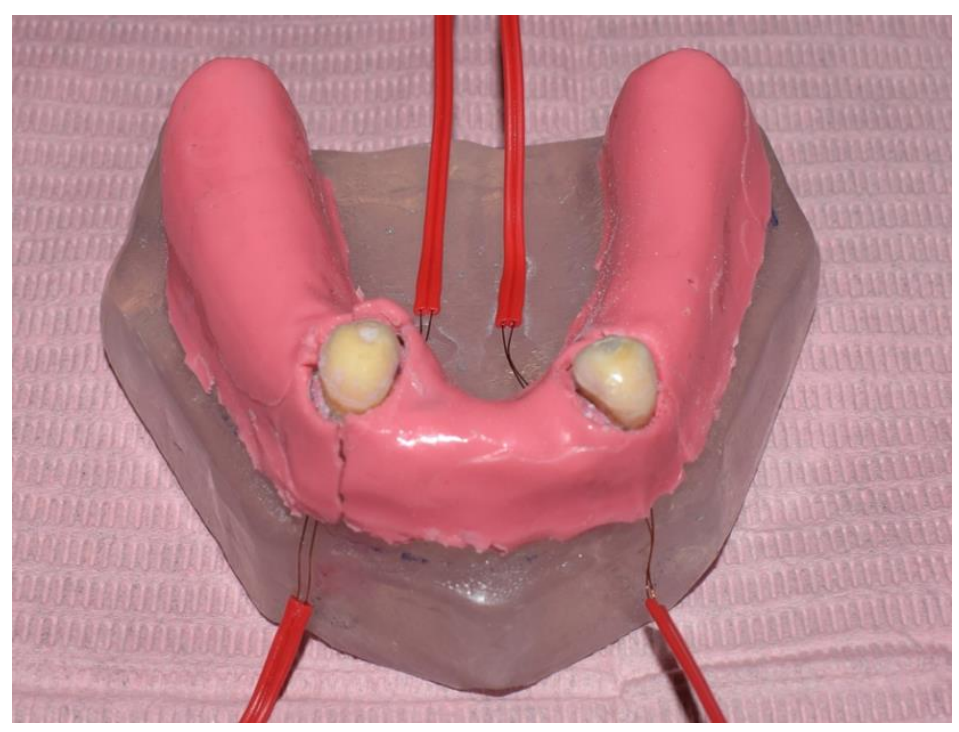

Figure 1a Strain gauge placed on the coronal one third of the abutments roots

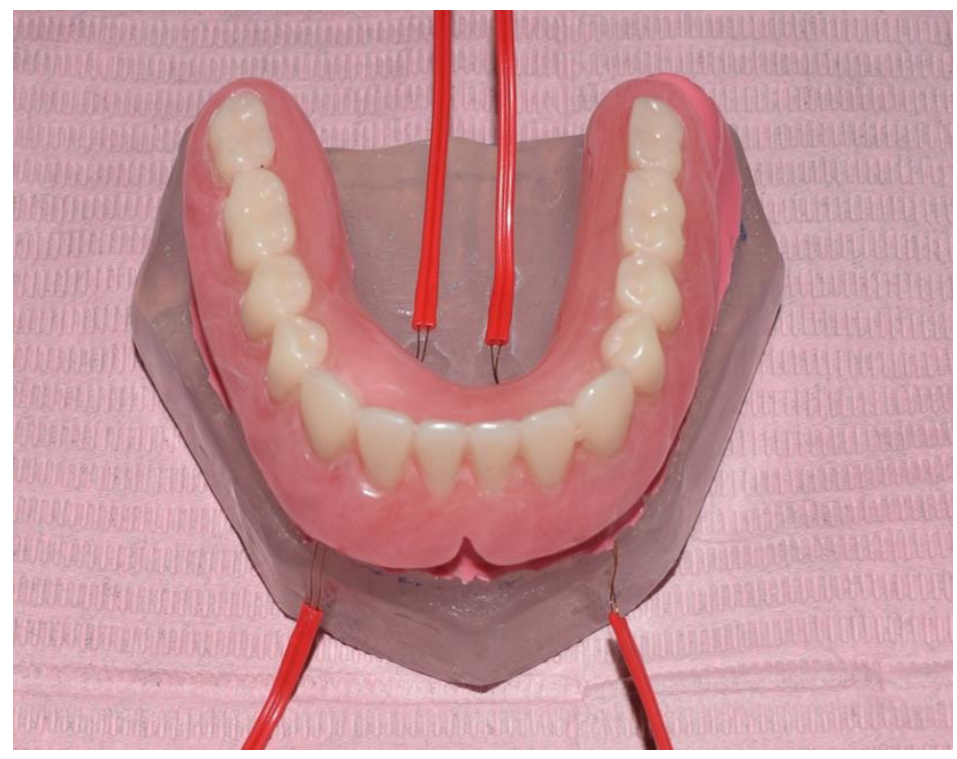

Figure $1 \mathbf{b}$ Over-denture placed on the pseudo realistic model with strain gauges

Results

Table 1 showing mean values of micro strain $(\mu \varepsilon)$ induced in teeth obturated with both techniques. ${ }^{*} \mathrm{P}<0.05$ is considered significant
Statistical analysis showed that strain induced within teeth obturated using lateral condensation technique was significantly higher than strain induced in teeth obturated by vertical compaction. 
Table 1. Showing mean values of micro strain $(\mu \varepsilon)$ induced in teeth obturated with both techniques.

\begin{tabular}{|c|c|}
\hline Vertical compaction & Lateral compaction \\
\hline $4.875 \pm 3.555$ & $85.25 \pm 104.901^{*}$ \\
\hline
\end{tabular}

* $\mathrm{P}<0.05$ is considered significant

\section{Discussion}

A load of $50 \mathrm{~N}$ was applied on the over-denture and the abutments supporting it, and data was interpreted. Our results showed that strain induced within the teeth obturated by lateral condensation was significantly higher than that induced in teeth obturated by vertical compaction. This might be due to the latent influence of lateral compaction forces on the root canal dentin. The potential presence of preexisting microcracks from either pre-existing or iatrogenic origin could be added to that stresses induced during lateral condensation forces to cause the propagation of such cracks reaching full-thickness fracture of the root dentin. This is in agreement with BROSH et al 12 and SHEMESH et al. 13, who showed that microcracks were induced in the root dentin by rotary instrumentation in addition to stresses induced during lateral compaction resulting in vertical root fracture.
Another possible cause is the higher volumetric portion of set cement in cases of lateral condensation in comparison to vertical condensation which is in full agreement with WU et al 14 and HUGH et al 15. The lower modulus of elasticity of the set cement does not favor the formation of a mechanically homogenous unit with the radicular dentin WILLIAMS et al. 16.

The inability of the root canal sealer to increase the root resistance to fracture might be attributed to the limited creeping ability of the sealer inserted into radicular canal that resulting in failures at the sealer/dentin interface TAY et al.17. More over, the bonding ability of resin sealer may also be influenced by the very high C-factor of root canals that leads to failure in the bonding ability of the filling material TAY et al.18.

\section{Conclusion}

Within the limitation of the study it can be concluded that the abutments treated with vertical obturation techniques reduced the stresses induced to the supporting structures when compared with the lateral condensation technique. Less forces transmitted means less reliability of fracture of the abutments and thus better prognosis of the tooth supported over-denture. Based on the previous results it can be recommended that during the fabrication of conventional overdenture supported by non-vital teeth, that vertical obturation technique should be advocated during the endodontic treatment of the abutments.

\section{Acknowledgment}

All authors declare that the research was done by self-funding, no any other source of funding was received. All authors contributed to conception, design, data acquisition and interpretation, performed all statistical analyses, drafted and 
critically revised the manuscript.

"All authors gave their final

approval and agree to be

accountable for all aspects of the

work."

\section{Conflicts of interest}

All authors declare that there is no conflict of interest in this research

\section{References}

1- Ettinger RL, Qian F. Abutment tooth loss in patients with overdentures. J Am Dent Assoc. 2004 Jun;135(6):739-46

2- Elsherbini AN. Mini-Poll Coping As An Alternative Attachment In Tooth Supported Over-Denture Prosthesis. Egyptian Dental Journal. 2019 Oct 1;65(4-October (Fixed Prosthodontics, Dental Materials, Conservative Dentistry \& Endodontics)):3671-5.

3- Chhabra A, Chhabra N, Jain A, Kabi D. Overdenture Prostheses with Metal Copings: A Retrospective Analysis of Survival and Prosthodontic Complications. Journal of Prosthodontics. 2019 Oct;28(8):876-82.

4- Nikolovska J, Petrovski D, Petricevic N, Kapusevska B, Korunoska-Stevkovska V. Overdentures on Implants for Better Quality of Life Among the Fully Edentulous Patients-Case Reports. prilozi. 2015 Dec 1;36(2):225-34.
5- Schuh C, Skupien JA, PereiraCenci T, Boscato N. Five-year of tooth-supported overdenture as prosthetic solution for elderly patients: A case series. Revista Odonto Ciência. 2014;29(1).

6- Cehreli MC, Karasoy D, Kökat AM, Akça K, Eckert S. A systematic review of marginal bone loss around implants retaining or supporting overdentures. Int J Oral Maxillofac Implants. 2010 Mar-Apr;25(2):266-77.

7- Nguyen TN. Obturation of the root canal system. Pathways of the pulp. 1994;6:219-71.

8- Weller RN, Kimbrough WF, Anderson RW. A comparison of thermoplastic obturation techniques: adaptation to the canal walls. Journal of endodontics. 1997 Nov 1;23(11):703-6.

9- Soros C, Zinelis S, Lambrianidis T, Palaghias G. Spreader load required for vertical root fracture during lateral compaction ex vivo: evaluation of periodontal simulation and fracture load information. Oral Surgery, Oral Medicine, Oral Pathology, Oral Radiology, and Endodontology. 2008 Aug 1;106(2):e64-70.

10- Budd CS, Weller RN, Kulild JC. A comparison of thermoplasticized injectable gutta-percha obturation techniques. Journal of Endodontics. 1991 Jun $1 ; 17(6): 260-4$.
11- Telli C, Gülkan P, Günel H. A critical reevaluation of stresses generated during vertical and lateral condensation of guttapercha in the root canal. Dental Traumatology. 1994 Feb;10(1):10.

12- Brosh T, Metzger Z, Pilo R. Circumferential root strains generated during lateral compaction with stainless steel vs. nickel-titanium finger spreaders. European journal of oral sciences. 2018 Dec;126(6):518-25.

13- Shemesh $\mathrm{H}$, Bier CA, Wu MK, Tanomaru-Filho $\mathrm{M}$, Wesselink PR. The effects of canal preparation and filling on the incidence of dentinal defects. International endodontic journal. 2009 Mar;42(3):208-13.

14- Wu MK, Özok AR, Wesselink $P R$. Sealer distribution in root canals obturated by three techniques. International Endodontic Journal. 2000 Jul;33(4):340-5.

15- Hugh CL, Walton RE, Facer SR. Evaluation of intracanal sealer distribution with 5 different obturation techniques. Quintessence international. 2005 Oct $1 ; 36(9)$.

16- Williams C, Loushine RJ, Weller RN, Pashley DH, Tay FR. A comparison of cohesive strength and stiffness of Resilon and guttapercha. Journal of endodontics. 2006 Jun 1;32(6):553-5. 
17- Tay FR, Hiraishi N, Pashley DH, Loushine RJ, Weller RN, Gillespie WT, Doyle MD. Bondability of Resilon to a methacrylate-based root canal sealer. Journal of endodontics. $2006 \quad$ Feb 1;32(2):133-7.

18- Tay FR, Pashley DH. Monoblocks in root canals: a hypothetical or a tangible goal. Journal of endodontics. $2007 \mathrm{Apr}$ 1;33(4):391-8. 